Piotr Roszak

UMK, Toruń-UN, Pampeluna

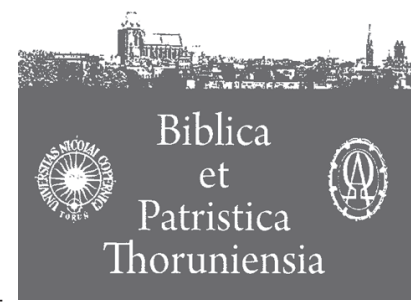

4 (2011) ISSN 1689-5150

\title{
Creación como relatio, assimilatio y processio En torno a la exégesis de santo Tomás de Aquino al Gen 1,1-2,3
}

\section{Creation as relation, assimilation and procession About Thomas Aquinas' exegesis of Gen 1:1-2:3}

\section{Stworzenie jako relatio, assimilatio i processio Wokół egzegezy św. Tomasza z Akwinu do Rdz 1,1-2,3}

Key words: medieval exegesis, creation ex nihilo, creation and Trinity, Thomas Aquinas.

Słowa kluczowe: egzegeza średniowieczna, stworzenie ex nihilo, stworzenie i Trójca Święta, Tomasz z Akwinu.

To encontraremos en el canon de las obras de santo Tomás de Aquino un comentario al libro del Genesis, porque no fue objeto de sus clases Pagina, pues así la época medieval denominaba a los profesores de teología ${ }^{1}$. Sin embargo, esto no quiere decir que no tengamos ninguna oportunidad para llegar y descubrir su principal estilo de interpretación de dicho libro. En el libro del Génesis encuentra santo Tomás una rica fuente para la reflexión teológica: simplemente repasando el número de citas de este primer libro de la Sagrada Escritura nos damos cuenta de la importancia de su exégesis en la labor

1 G. Dahan, Les Éditions des commentaires bibliques de saint Thomas d'Aquin, Leur apport à la connaissance du texte de la Bible au XIIIe siècle, "Revue des Sciences Philosophiques et Theologiques" 89 (2005), 9-16. 
teológica. Le interesa al Aquinate la historia de Abrahan y de los patriarcas, pero sobre todo, se fija en el relato sobre la creación del mundo, presentando en base de la exégesis de dicho texto inspirado una interesante formulación teológica de esta verdad de la fe.

La teología cristiana consigue gracias al Aquinate una clara fórmula de la doctrina de la creación ex nihilo, su articulación con el lenguaje filosófico, aunque se formaba ya desde el mismo comienzo del cristianismo (basta mencionar a Ticiano, Teófilo de Antioquía, Ireneo, Tertuliano, Clemenso de Alejandría, Orígenes) ${ }^{2}$. En san Agustín y durante la temprana Edad Media se convierte ya en una idea teológica bien elaborada, aunque su exposición completa y madura está vinculada con personas como Moisés Maimónides (1135-1204), san Alberto Magno (1205-1280) y santo Tomás de Aquino (1225-1274) ${ }^{3}$.

En este artículo nos fijaremos primero en el profundo vínculo con la Sagrada Escritura que caracteriza el quehacer teológico en Aquinate; de ahí vienen sus comentarios bíblicos a los libros tanto del Antiguo como del Nuevo Testamento. Después de una característica general de su modo de tratar las citas del libro del Génesis, nos detendremos en el relato de creación (Gen 1,1-2,1) que con frecuencia suele citar santo Tomás. Es consciente de que se encuentra ante un texto de mucha importancia para la teología, lo cual se traduce en organizar la exposición de la verdad sobre la creación del mundo en la "Suma de teología" precisamente en la base del relato del Génesis. Estamos ante una situación curiosa, porque Tomás presenta su exégesis no como los escritores eclesiásticos de la patrística (en un género literario aparte), sino en obras sistemáticas, con "moldes aristotélicos". Nos atreveremos a examinar su modus procedendi en cuanto al libro del Génesis y así extraer su postura exegética, su teoría de los sentidos de la Escritura ya aplicados al texto del primer libro de la Biblia.

\section{Carácter bíblico de la teología del Aquinate}

En primer lugar, hay que subrayar que santo Tomás hace la exégesis como un teólogo sistemático que pregunta por lo esencial apoyándose en el lenguaje

2 Cfr. D. Cerbelaud, La création «ex nihilo» en question, "Revue thomiste" 90 (1990), 357-372; G. Cottier, La doctrine de la création et le concept de néant, "Acta Philosophica" t. 1/1 (1992), 6-17.

3 Cfr. A. Maryniarczyk, Kreacjonizm jako punkt zwrotny w interpretacji rzeczywistości, en: Filozofia - wzloty i upadki, XXXIX Tydzień Filozoficzny KUL, 3-6 marca 1997, Lublin 1998, 60-70. 
filosófico, porque le parece el más universal ${ }^{4}$. Si se quiere hablar con credibilidad, hay que buscar una común plataforma del pensamiento ${ }^{5}$. Su lectura del Génesis será marcada, pues, por la pregunta sobre la distancia ontológica entre la creación y el Creador, pero por otro lado, también por la profunda convicción metafísica de la congruentia (expresada también por la convenientia, un término de mucha importancia para santo Tomás ${ }^{6}$ ): ésta ocurre gracias al Logos como Aquel en quien todo fue creado.

Tomás lee el libro del Génesis como un teólogo que opta por el principio locus ex loco, o sea, en captar el sentido de cada fragmento de la Sagrada Escritura con la ayuda del otro, en definitiva de toda la historia de la salvación. Si hubiera surgido su comentario al Génesis, sin duda podría parecerse a aquellos que conocemos sobre el libro de Job, Salmos o incluso de su juventud, como Isaías o Trenes de Jeremías. Son unos comentarios que no son - como lo practicaba por ejemplo Avicenna al comentar las obras de Aristóteles - una simple paráfrasis, sino captar una principal línea temática. Por tanto, éstos comentarios tomistas analizan verso tras verso, sin aspirar a ser una síntesis completa de la correspondiente materia teológica. No obstante, durante sus dieciocho años de actividad académica del Aquinate, formaban su principal tema de clases y un punto de referencia para todas las disputatio con las que vivían todas las facultades de teología de aquel entonces ${ }^{7}$. El lenguaje de la sacra doctrina estaba en profunda simbiosis con el lenguaje metafísico y por lo tanto en el lector moderno igual puede provocar a veces alguna duda y asombro que en general es posible cultivar este estilo - sintético y harmónico - de exégesis ${ }^{8}$.

4 X. Tilliette, Les philosophes lisent la Bible, coll. Philosophie et Théologie, Cerf, Paris 2001, 78-83.

5 Cfr. O. Riaudel, Le monde comme histoire de Dieu, coll. Cogitatio Fidei, 256, Paris 2007, 204-212, 340-342, 378-379 (alusiones a santo Tomás y su doctrina de la creación en el contexto del pensamiento de Pannenberg); también: R. Bellemare, La Somme de Théologie et la lecture de la Bible, Colloque commémoratif Saint Thomas d'Aquin 1274-1974, t. 2, Église et Théologie, 5, Université Saint Paul, Ottawa 1974.

6 Se trata de un método específico de argumentar que desarrolla santo Tomás en sus obras teológicas que llegó a denominarse como ex congruo o de congruo. Cfr. Ph.-M. Margelidon, Y. Floucat, Dictionnaire de philosophie et de théologie thomistes, Parole et Silence, Paris 2011, 80; cfr. también S. Th., I-II, q. 114, a. 6-7.

7 Cfr. P. Roszak, Disputatio en la vida de la universidad medieval a la luz del Verbum Abbreviatum de Pedro Cantor, en: Dysputy Nawarryjskie w Toruniu, red. P. Roszak, KPTKO, Toruń 2010, 149-162.

8 Cfr. M. Mróz, P. Roszak, Perfectus secundum intellectum et affectum. Ideał egzegety i jego pracy komentatorskiej wg Tomasza z Akwinu, “Teologia i Człowiek” 10 (2007), 113-130. 
No es posible comprender en el fondo esta práctica teológica de santo Tomás sin fijarse en el papel que juegan las citas bíblicas que aparecen en la argumentación. Tienen un papel hermenéutico importante para el pensamiento: están construyendo una red escripturística argumentativa que permite descubrir la ideas teológicas tomasianas en su contexto más amplio.

\section{Comentarios bíblicos de santo Tomás al Antiguo Testamento}

Cada vez es más frecuente que los conocedores del pensamiento del Angélico para exponer algunas ideas particulares de santo Tomás presten atención a sus comentarios bíblicos al Antiguo Testamento. No cabe duda de que no siempre han recibido la atención que merecen. Santo Tomás en su trabajo del magister in Sacra Pagina comentaba los libros del Antiguo Testamento en diferentes etapas de su vida. En muchas ocasiones, los expertos difieren en la datación de cada uno de los comentarios y su carácter, pues en el canon de las obras del Aquinate encontramos comentarios muy diferentes en su estilo y forma. Basta comparar su juvenil comentario al libro de Isaías, probablemente vinculado con su puesto de bacalario bíblico, con la Lectura super Psalmos que representa ya una obra madura y en definitiva es el último comentario bíblico. Tomás dedicó su atención también al libro de Trenos de Jeremías y sobre todo al libro de Job, buscando en su contenido la respuesta a la pregunta tan importante: ¿Por qué sufren los buenos?

La hermenéutica teológica del Aquinate que emana de sus comentarios bíblicos está relacionada no solamente con la comprensión (sensus) del particular pasaje de la Sagrada Escritura, sino también con la cumulación? Ninguna frase es entendida en una 'isolación interpretativa', sino consecuentemente 'inscrita' en el marco de la tradición: Tomás es consciente de que no es el primer comentador del texto bíblico, por eso tantas veces incorpora su propia opinión o postura a la cadena de la tradición exegética de los siglos anteriores ${ }^{10}$. De esta manera, construye una especie de 'ambiente hermenéutico' que lleva a un tipo específico de la exégesis teológica: el interpretador se deja guiar por los ojos de la fe - con toda la riqueza que

9 M. Levering, Participatory Biblical Exegesis. A Theology of Biblical Interpretation, University of Note Dame Press, Note Dame 2008, 123.

10 Cfr. J. A. Di Noia, Christ brings freedom from sin and death: the commentary of st. Thomas Aquinas on Romans 5:12-21, “The Thomist” 73 (2009), 385. 
gracias a esto es ya su parte - para descubrir el mensaje integrador y escondido al mismo tiempo que abraza toda la Revelación ${ }^{11}$. Será una exégesis que con el paso del tiempo se va a denominar la 'canónica'12.

\section{Rasgos característicos de la exégesis del Aquinate al Libro del Génesis}

Antes de ir al análisis de los principales motivos exegéticos del Aquinate, merece la pena preguntarse por su ambiente hermeneutico. Tomás al interpretar el libro del Génesis principalmente cita a las dos auctoritas - san Ambrosio y san Agustín - cuyos comentarios fueron muy difundidos y apreciados en la época medieval ${ }^{13}$. Ya por la misma frecuencia de las citas se nota claramente que el Aquinate se ajusta a la principal explicación agustiniana (sobre todo sacada de In Gen ad litteram, pero no solamente de aquella obra, sino también a menudo se apoya santo Tomás en Enchiridion o De civitate Dei o ad Orosium), pero incluye también las interpretaciones de otros padres de la Iglesia (principalmente orientales), como san Basilio ${ }^{14}$, san Juan Crisóstomo ${ }^{15}$ y san Juan Damásceno ${ }^{16}$. Sin embargo, claramente le irrita la explicación alegórica de Orígenes ${ }^{17}$. Todo esto lleva a una peculiar "exégesis dialógica" que cultiva el Aquinate - consciente de que vale la pena escuchar también a los demás y no aferrarse a una única interpretación, sobre todo por razones pastorales ("cuando la Escritura divina pueda ser explicada de muchas maneras, que nadie se aferre a una exposición de tal forma que, si se constata que es falsa la opinión que defiende, le impida admitir otro sentido del texto de la Escritura, no sea

11 Lo subraya también H. Gadamer, Prawda i metoda. Zarys hermeneutyki filozoficznej, Kraków 1993; un interesante comentario a las cuestiones hermenéuticas de Gadamer encontramos en M. Szulakiewicz, Filozofia jako hermeneutyka, WN UMK, Toruń 2004, 94-98.

12 Benedicto XVI, Adhortación Apostólica Verbum Domini.

13 Cfr. U. Horst, Das Wesen der "auctoritas" nach Thomas von Aquin, "Munchener Theologische Zeitschrift“ 13 (1962), 155-172; cfr. también: M.-D. Chenu, Wstęp do filozofii św. Tomasza z Akwinu, tłum. H. Rosnerowa, Kęty 2001, 120-142.

14 S. Th., I, q. 66, a. 1 , ad 1.

15 Más sobre esta influencia, cfr: P.-Y. Maillard, "Christus clarificatus in passione": l'influence de Jean Chrysostome sur Thomas d'Aquin. Un exemple, "Nova et Vetera" 4 (2010), 365-381.
16 S. Th., I, q. 70 a. 3 c.
17 S. Th., I, q. 68 , a. 2c. 
que se ridiculice la Escritura ante los no creyentes y se les cierre un posible acceso para creer"18).

$\mathrm{Si}$ hubiéramos querido reconstruir los temas teológicos que expone el Aquinate apoyándose en las citas del Gen, en varias de sus obras sistemáticas, pero también otros comentarios bíblicos al Antiguo y Nuevo Testamento, sin ninguna duda ocupan un lugar central las cuestiones relacionadas con la creación del mundo y del hombre. Se trata tanto de la idea de la creación ex nihilo, con toda clase de cuestiones que se abren ante un teólogo: la pregunta por la eternidad del mundo, el fundamental asunto de la "participación" y "analogía del ente", la referencia al misterio de la Santísima Trinidad o la naturaleza del acto creador y la conservación del mundo en la existencia ${ }^{19}$. Pero santo Tomás hace referencia al libro del Génesis también en otras ocasiones, volviendo a las historias contadas por este libro. Claramente le interesa la historia de Abrahan (en el contexto de la pregunta sobre la obediencia a los mandatos de $\operatorname{Dios}^{20}$ ) y otros motivos particulares, imágenes (como los castros de Jacob del Gen 32,2) que sirven de metáfora para la Iglesia y abren interesantes interpretaciones eclesiológicas ${ }^{21}$.

Al presentar el estilo de exégesis del Aquinate fijaremos nuestra atención en su modo de interpretar un texto-clave para toda la teología cristiana: Gen 1,1$-2,3$. En primer lugar nos detendremos en el esquema general del pensamiento tomista o modelos interpretativos que descifran el mensaje del Génesis con un lenguaje filosófico. Luego, nos centraremos ya en la explicación detallada de la obra de la creación para terminar con un intento de valoración de la exégesis Tomasiana del libro del Génesis basada en otros comentarios bíblicos.

\subsection{Interpretación del relato de la creación}

Frecuentemente, santo Tomás cita la primera frase del libro del Génesis en el sed contra de Suma de teología como un argumento escripturístico más

18 S. Th., I, q. 68, a. 1c.

19 Cfr. T.-D. Humbrecht, Trinité et création au prisme de la voie négative chez saint Thomas d'Aquin, Parole et Silence, Paris 2011, 100-134. El autor ofrece una interesante mirada desde la perspectiva de la teología negativa presente en los escritos del Aquinate. De alguna manera complementa los estudios de G. Emery.

20 M.V. Dougherty, Thomas Aquinas and Divine Command Theory, en: M. Baur (ed.), Philosophy at the Boundary of Reason, "Proceedings of the American Catholic Philosophical Association" 76 (2002), 153-164. Autor hace unas interesantes comparaciones entre el modo de interpretar la historia de Abrahan en Kierkegaard y Aquinate.

21 In Coll., prol. 
importante en el tema ${ }^{22}$. Se acerca al misterio de la creación con actitud filosófica, que se expresa en enfocar el tema de manera que integre las dos visiones principales: la "participación" platónica y la teoría de las causas de Aristóteles ${ }^{23}$. Son las claves para la lectura tomasiana del texto del Gen 1,1$-2,3$. De ellas sale la particular visión filosófica que concuerda con las ideas que presenta la Revelación.

La frase en principio Dios creó el cielo y la tierra, para santo Tomás subraya ante todo la principal prerogativa de Dios: sólo Él puede crear en sentido propio de la palabra ${ }^{24}$. Naturalemente, la palabra 'crear' se emplea en diversos aspectos (cuando se lleva a uno a la dignidad más alta ${ }^{25}$ ), pero para el Aquinate lo más importante es indicar que "todo" proviene de Dios como causa universal de todo el ente. Por tanto, al recoger las interpretaciones existentes, Tomás propone tres lecturas de la frase en principio: en sentido temporal (en principio del tiempo, recordando así que el mundo y el tiempo no existen desde siempre, sino que fuero creados "juntos"), en sentido cristológico ("en el Hijo", comprendido aquí como causa ejemplar ${ }^{26}$ ) y en sentido que excluye la mediación de otras criaturas (de ahí se entiende en principio como 'ante todo') ${ }^{27}$. Merece la pena prestar la atención en tres modelos interpretativos más fundamentales que ofrece el Aquinate, que son fruto de su lectura de los primeros capítulos del Génesis: se convierten al mismo tiempo en el intento de traducir la verdad de la creación del lenguaje bíblico al filosófico, es decir que tiene pretensión de ser universalmente válido ${ }^{28}$.

22 S. Th., I, q. 45, a. 2: "sed contra est quod super illud Gen. I, in principio creavit Deus caelum etc."

23 Cfr. T. Pawlikowski, Zagadnienie akty stwórczego w kwestii 44 części I Sumy Teologicznej św. Tomasza z Akwinu, "Seminare” 25 (2008), 191-204.

24 Tomás dedica todo el articulo para explicar esta cuestión: S. Th. I, q. 45, a. 6.

25 S. Th., I, q. 45, a. 1, ad 1; cfr. también: S. Th., I, q. 65, a. 3c: "La creación es la producción de algo en toda su sustancia n sin presuponer nada increado o creado por alguien. Así, hay que concluir que nadie puede crear algo. Sólo Dios, que es la primera causa, puede hacerlo. Fue así como Moisés, viendo que todo había sido creado directamente por Dios, dijo: En el principio creó Dios el cielo y la tierra”.

26 Cfr. In Coll., cap. I, lect. 4 (n. 38): Gen 1, 1: "in principio, id est in filio, creavit Deus, et cetera".

27 Es una exégesis del Gen 1,1 que desarrolla el Aquinate en $S$. Th., I, q. 46, a. 3c.

28 Cfr. L. Dewan, St. Thomas, Aristotle, and Creation, "Dionysius" 15 (1991), 81-90; M.-A. Vannier, Sur le problème de la création, Réflexion en marge des textes de saint Thomas, en: Problemi Metafisici. Atti dell' VIII ${ }^{\circ}$ Congresso Tomistico Internazionale, V, Libreria Editrice Vaticana, Roma 1982, 435-451. 


\subsubsection{Creación como procedencia (processio)}

La exégesis tomasiana del Gen 1 está metida en los marcos interpretativos amplios, de carácter filosófico y que hacen referencia a la idea más general: la proveniencia de Dios. Santo Tomás procede así por razón de incluir el misterio de la creación en la perspectiva trinitaria, según la cual la creatio es percibida en el contexto de la procedencia de las Personas en la Santísima Trinidad $^{29}$ y gracias a esto recibe una profundización ${ }^{30}$. Las procedencias intratrinitarias - sobre todo la generación del Hijo - son para Tomás-teólogo el primer punto de reflexión y un constante punto de comparación entre uno y otro tema, porque son la ratio y la causa de la procedencia de las criaturas ${ }^{31}$.

Adentrándose en los textos del Génesis, Tomás descubre la verdad de la fundamental dependencia del mundo de Dios. La describe con un término importante desde el punto de vista de la tradición filosófica processio que tiene una amplia gama de significados: se la emplea para denominar el movimiento local, pero también un cierto orden unius ex alio vel post aliud ${ }^{32}$. De todas maneras indica un principio general de causalidad. Es una afirmación bastante general que no explica el modo en el que ocurre esta procedencia. En su fundamento se encuentra una acción (actio) que corresponde a la naturaleza del mismo Dios Creador. Se trata entonces de comprender la creación como una actividad que hace algo de la nada, tiene carácter inmanente respecto a Dios y al mismo tiempo, por su objeto ad quem, pasajero (que se detiene en la creación sólo 'virtualmente". El acto de creación aparece como perfecto, siendo un 'regalo del ser' ${ }^{33}$ : por eso la obra de la creación puede ser percibida como una actuación que aporta a los seres creados el propio acto del ser. El ser

29 Esta regla fundamental del Aquinate refleja ya el mismo esquema de sus escritos sistemáticos (sobre todo el comentario a las Sentancias o Suma de teología), en los que este tema de la creación - apoyado en la exégesis de los relatos del libro del Génesis, se explica justo después de presentar el misterio de la Santísima Trinidad. Cfr. G. Emery, F. Murphy. The Trinitarian Theology of St Thomas Aquinas, Oxford University Press, Oxford 2007.

30 Cfr. S. Th., I, q. 32, a. 1, ad 3: "cognitio divinarum personarum fuit necessaria nobis dupliciter. Uno modo, ad recte sentiendum de creatione rerum. Per hoc enim quod dicimus Deum omnia fecisse Verbo suo, excluditur error ponentium Deum produxisse res ex necessitate naturae. Per hoc autem quod ponimus in eo processionem amoris, ostenditur quod Deus non propter aliquam indigentiam creaturas produxit, neque propter aliquam aliam causam extrinsecam; sed propter amorem suae bonitatis".

31 Cfr. In I Sent., d. 10, q. 1, a. 1, sol: "oportet processionem personarum quae perfecta est, esse rationem et causam processionis creaturae".

32 De Potentia, q. 10, a. 1c.

33 S. Th., I, q. 9, a. 2c. 
de la creación es siempre un ser "recibido". Por tanto, si vamos a considerar la creación en sí misma, sin referencia a Dios Creador, de nuevo vuelve a la nada, el vacío de no-existencia.

\subsubsection{Creación como relación (relatio)}

Precisamente por esto, la creación comprendida como "regalar el ser" en modo de procesión, tiene que ser entendida como una relación pura, pero como relación que se encuentra en el mismo orden del ser creado ${ }^{34}$. Por este motivo, el ser no está "enraizado" eternamente en cada ser, porque siempre está en relación con la acción donacional del Creador. Todo esto nos recuerda, observa el Aquinate, que la acción creadora no puede ser pensada como un mero movimiento ${ }^{35}$.

La exégesis del Gen 1,1-2,3 lleva al Aquinatense a la convicción de que el misterio de la creación no es en el fondo una teoría acerca de cómo surgieron todas las cosas (que es la eterna tentación de la lectura fundamentalista), sino la manera de percibir todo en relación a Dios. Alabando la teología tomista de la creación, el arzobispo de Canterbury R. Wiliams subraya que según el Aquinate nunca deberíamos pensar en la creación como en un acontecimiento con un "antes" y un "después" o como un mero cambio de situación (pasar del caos a la existencia), sino como una acción de Dios que establece relaciones entre sí mismo y todo lo demás ${ }^{36}$. Santo Tomás lo expresará en categorías de su lenguaje escolástico hablando de un esse ad aliud. Para el Aquinate, la creación es una relación real que puede ser percibida activa o pasivamente: como acción de Dios (entonces es una 'relación lógica', porque no cambia nada en Dios cuando crea) o como su terminus, osea el fruto de esta acción - es decir, la creación misma. Dios como realmente creador es capaz de hacer algo radicalmente nuevo, lo que no significa para el ser ninguna degradación, sino perfección ${ }^{37}$. 1968, 57.

34 J. Rassam, Le métaphysique de saint Thomas, Presses Universitaires de France, Paris

35 F. D. Wilhelmsen, Creation as a Relation in Saint Thomas Aquinas, "The Modern Schoolman" 56 (1979) 107-133.

36 Cfr. R. Williams, Tokens of Trust. An introduction to Christian belief, Canterbury Press, London 2007, 52.

37 Cfr. L. Dümpelmann, Kreation als ontisch-ontologisches Verhältnis: zur Metaphysik der Schöpfungstheologie des Thomas von Aquin, K. Alber, Freiburg 1969. Cfr. también S. Ford, Two types of creationist philosophy: Thomas and Whitehead, "Encounter" 4 (2002), 385-396. 


\subsubsection{Creación como asimilación a Dios (assimilatio)}

Merece la pena, sin embargo, otra aproximación al misterio de la creación que de manera muy característica para el Aquinate - metafísicamente precisa - pretende transmitir la verdad recogida del Gen 1. Lo expresa un término relacionado tradicionalmente con la tradición del Dionisio Areopágita assimilatio $^{38}$. El sentido del assimilatio revela la comparación de la relación entre Dios y la creación con el aire iluminado y el sol. La luz que hace transparente al aire es una acción que asimila el aire al sol y lo hace visible como la presencia del sol. De manera parecida, la creación asimila a Dios haciendo que Dios de alguna manera esté presente en ella ${ }^{39}$. Esta presencia de Dios en la creación hace que de ningún modo sea oculta la creación ante Él, sino vista en cierta "nudez" del ser"40.

\subsubsection{Exégesis que inspira la filosofía: dilema de la necesidad y eternidad del mundo}

Uno de los temas que ocupaban las mentes de la época del Aquinate y para responder a ellos se acudía al texto del Gen 1,1-2,3, era la cuestión "de la eternidad del mundo" que retoma santo Tomás en una pequeña obra suya titulada De aeternitate mundi ${ }^{41}$. La plantea al pensamiento cristiano la tradición filosófica de la antiquedad, que percibía la creación en plan de la emanación neoplatónica. No se trata, sin embargo, de este tipo de especulaciones, sino la pregunta - de carácter teológico, como intenta convencer Weisheip $1^{42}-$

38 Cfr. J. Pérez Guerrero, La creación como asimilación a Dios: un estudio desde Tomás de Aquino, Eunsa, Pamplona 1996, 176-180; cfr. también: A. Hofer, Dionysian elements in Thomas Aquinas's christology: A case of the authority and ambiguity of Pseudo-Dionysius, "The Thomist" 72 (2008), 409-442.

39 Cfr. S. Th., I, q. 8, a. 3c; cfr. también E. Gilson, El ser y los filósofos, 258.

40 Cfr. G. Cottier, La doctrine philosophique et théologique de la création chez Thomas d’Aquin, "Nova et Vetera" 84 (2009), 71-83.

41 M. A. Santiago de Carvalho, Le langage de la création et l'enjeu de la causalité dans quelques textes théologiques «De aeternitate mundi», en: J. Hamesse, C. Steel, éd., Lélaboration du vocabulaire philosophique au Moyen Âge. Actes du Colloque international de Louvain-laNeuve et Leuven (12-14 septembre 1998) organisé par la Société Internationale pour 1'Étude de la Philosophie Médiévale, coll. Rencontres de Philosophie Médiévale 8, Brepols, Turnhout 2000, 293-321.

42 J. Weisheipl, The Date and Context of Aquinas's De aeternitate mundi, en: Graceful Reason. Essays in Ancient and Medieval Philosophy Presented to Joseph Owens, red. J. Gerson, Toronto 1983, 239-271. 
se refiere a la eternidad del mundo después de su creación. Tomás considera esta cuestión en el contexto de la fe cristiana que reconoce a Dios como "causa" de la creación (causa agens scilicet Deus ${ }^{43}$ y no permite pensar en Dios de tal manera que esto supusiera tratar la creación como co-aeternus al Creador ${ }^{44}$. Claramente lo expresa la idea defendida por el Aquinate de la creación ex nihilo - por ejemplo en S. Th., I, q. 61, a. 2c.: postquam nihil fuerat.

El fondo de la cuestión que abarca santo Tomás - que solamente señalamos como un ejemplo de un cierto modo de cultivar la exégesis que sirve de base para las futuras consideraciones filosóficas - se refiere a la distinción entre contingentia y temporalitas, pero también la posibilidad de la "infinitud" in potentia que permite mostrar la creación del mundo sin tomar en cuenta su temporalitas ${ }^{45}$. Tomás asegura que el mundo puede ser eterno, pero eso no quiere decir que sea así ${ }^{46}$. De manera parecida trata el tema de la "necesidad" de la creación del mundo - idea tan característica para algunas corrientes intelectuales de su época, por mencionar solamente a los neoplatónicos o emanacionistas - en santo Tomás, esta cuestión se soluciona con los datos de la Revelación que muestran la libertad "absoluta" del acto creador, aunque esto no contradiga que este acto creador tenga una lógica propia - una vez iniciado el acto creador por su propia voluntad - que se expresa con un tipo específico de la necesidad 'final' (ex conditione) ${ }^{47}$.

43 De aeternitate mundi, 88. Lo subrayan también otras numerosas frases, como: Deus est causa... Deus causat per voluntatem...

44 Sin duda, este opusculum de santo Tomás merece una peculiar atención - importante también para los análisis sobre la exégesis tomasiana del libro del Génesis - por sus reflexiones acerca de la naturaleza del lenguaje teológico. El tratado es un intento de precisar el significado del término 'aeternus' que se refiere a la Santísima Trinidad y también de fijar el papel de la analogía en las descripciones del mundo. Por. D. Burrell, God's Eternity, "Faith and Philosophy" 1 (1984), 389-406.

45 Más sobre las consecuencias teológicas y filosóficas de esta discusión en: O. Argerami, La cuestión 'De aeternitate mundi': posiciones doctrinales, "Sapientia" 27 (1972), 313-334; F. J. Kovach, The Question of the Eternity of the World in St. Bonaventure and St. Thomas: A Critical Analysis, "The Southwestern Journal of Philosophy" 5 (1974), 141-172; J. A. Artsen, The eternity of the world: the believing and the philosophical Thomas. Some comments, en: The eternity of the world: in the thought of Thomas Aquinas and his contemporaries, red. J. B. M. Wissink, Brill, Leiden 1990, 9-19; I. M. Azcoaga, La razón y la fe ante la creación temporal del mundo, "Revista Española de Filosofía Medieval" (1993) 31-38.

46 O. Argerami, Ortodoxia y heterodoxia en la disputa "De aeternitate mundi", "Patristica et Medievalia" 3 (1982), 11.

47 Cfr. J. M. Hallmann, The necessity of the world in Aquinas and Whitehead, "The Modern Schoolman" 4 (1983), 266-269. 


\subsection{Exégesis del Gen $1,1-2,3$ según el Aquinate: creatio, distinctio, ornatio}

Una vez presentados los modelos generales de interpretación de la creación del mundo que utiliza santo Tomás en su labor teológica, nos detendremos ahora en la exégesis detallada del mismo relato bíblico. El Aquinate fijándose en el texto del Libro de Génesis distingue una triple estructura que corresponde a las tres "obras" que forman parte de la obra de la creación. Lo refleja la triada de tres palabras latinas: opus creationis (obra de la creación), opus distinctionis (obra de la diversificación) y opus ornationis (obra de la ornamentación) ${ }^{48}$. Ha de subrayarse que este modo de clasificar y dividir el texto bíblico, apoyándose en el criterio de las obras que Dios realiza en la historia, es un rasgo característico de la exégesis tomasiana al Antiguo Testamento (un esquema parecido presenta santo Tomás en su exégesis del libro de los Salmos $\left.{ }^{49}\right)$.

\subsubsection{Opus creationis}

El punto de partida de la exégesis del Aquinate respecto a la obra de la creación es la pregunta por la naturaleza del acto creador que no consistía simplemente como creían los filósofos antiguos - en la formación u ordenación de la materia (como un demiurgo) que existía antes en caos (o hablando el lenguaje metafísico en solamente "dar la forma"). Tomás interpreta creó en sentido de ex nihilo como creación de la materia también. Su atención llaman, sin embargo, las palabras: "la tierra era caos y vacío, la tiniebla cubría la faz del abismo" (Gen 1,2). De esta manera explica su significado santo Tomás: "Con respecto al texto del Gén 1,2, la ausencia de proporción, por la que se decía que el estado de lo creado era informe, era triple. Pues al cuerpo totalmente transparente, el cielo, le faltaba la belleza de la luz. Por eso se dice: Las tinieblas cubrían el abismo. A la tierra le

48 S. Th., I, q. 70, a. 1c: "En la recapitulación de las obras divinas, la Escritura dice (Gén 2,1): Así, pues, fueron acabados los cielos y la tierra y toda su ornamentación. En estas palabras puede entenderse la triple obra: la de creación, por la que se dice que fueron hechos el cielo y la tierra, si bien en estado informe; la de diversificación, por la que el cielo y la tierra fueron acabados, tanto por las formas sustanciales atribuidas a la materia informe, según Agustín 1, como por lo que respecta a la adecuada ornamentación y orden, según otros santos. Y a estas dos obras se añade la de ornamentación".

49 In Ps., prooemium. Los salmos - según el Aquinate - temáticamente hacen referencia o las obras grandes de Dios: "Est autem quadruplex opus Dei: scilicet creationis: Gen. 1 cap.: requievit Deus die septimo ab omni opere et cetera. Gubernationis: Joan. 5: pater meus usque modo operatur et cetera. Reparationis: Joan. 4: meus cibus est ut faciam voluntatem ejus qui misit me, ut perficiam opus ejus. Glorificationis: Eccl. 42: gloria domini plenum est opus ejus. Et de his omnibus complete in hac doctrina tractatur". 
faltaba una doble belleza: la de estar libre de las aguas, por eso se dice que estaba deshabitada, o que era invisible, puesto que no se podía ver cómo era por estar cubierta de agua. La otra belleza, la presencia de hierbas y plantas; por eso se dice que estaba vacía, o sin componer, sin ornamentación, según otra versión" ${ }^{\prime \prime}$.

La exégesis del Aquinate retoma unos sutiles motivos metafísicos, identificando - nota bene, tras san Agustín - "cielo" y "tierra" con la materia prima $^{51}$ o con el mismo elemento físico (como postulaban otros Padres de la Iglesia $)^{52}$ o por el cielo "naturaleza espiritual todavía informe" y por la tierra "materia informe de la criatura corporal" 53 . Las tinieblas las interpreta como la falta de luz y signo de la sabiduría divina que establece que los seres creados de la nada primero se encuentran en el estado de la imperfección para pasar con el tiempo a la perfección. Este camino hacia la perfección es designado con las dos siguientes obras. De ahí que la creación del mundo exija una lectura sapiencial, capaz de contemplar la sabiduría del designio de Dios ${ }^{54}$, conscientemente evitando el debate sobre las cuestiones detalladas de la cosmología (dedicados, por citar un ejemplo, a la existencia del cielo empíreo, postulado por tantos autores patrísticos y medievales, como san Basilio, Estrabo, Bede el Venerable), propios de la imaginación colectiva de su época.

\subsubsection{Opus distinctionis}

La atención del Aquinate en el relato de la creación en Gen 1,1-2,3 llama a una manera de describir dicho acto creador que subraye numerosas distinciones (diversificaciones) de una realidad de la otra, aunque en general santo Tomas distingue dos tipos, diríamos, de diversificaciones.

50 S. Th., I, q. 66, a. 1c. Todas las citas de la Suma de teología provienen de la edición dirigida por los Regentes de Estudios de las Provincias Dominicanas en España y publicada por la BAC en 2001.

51 S. Th., I, q. 66, a. 1, ad 1: "Sin embargo, guarda semejanza con la tierra en cuanto que se asienta bajo la forma; y con el agua en cuanto que se adapta a muchas formas".

52 Cfr. W. E. Carroll, Thomas Aquinas on Science, 'Sacra Doctrina', and Creation en: J. Meer, S. Mandelbrote (red.), Nature and Scripture in the Abrahamic Religions: Up to 1700, v. 1, Brill, Leiden 2008, 219-248.

53 S. Th., I, q. 67, a. 4c; w q. 68, a. 4. Tomás propondrá una sistematización del concepto del "cielo", indicando sus tres significativos que aparecen en la Sagrada Escritura: en sentido natural (introduciendo la división en 8 sectores del cielo), en sentido de poseer una característica del cuerpo celestial y en sentido metafórico (que permite denominar la Santísima Trinidad como un cielo).

54 S. Th., I, q. 66, a. 3c. 
La primera tiene carácter introductorio y se refiere al cielo y la tierra ("En el principio creó Dios el cielo y la tierra"), luego diversificación "de los elementos en cuanto a sus formas" (tierra y agua; aire y fuego ${ }^{55}$ ). Aunque directamente no se menciona al fuego y al aire, sin embargo santo Tomás conociendo la exégesis patrística y contemporánea asimismo, observa que algunos (Agustín) identificaban al "espíritu de Dios" con el aire, fuego con la "oscuridad" (Moisés Maimónides ${ }^{56}$ ). Tomás interpreta al "espíritu de Dios" en sentido trinitario, convencido de que significa al Espíritu Santo que "Y se dice que se desliza sobre las aguas, pero no corporalmente, sino como la voluntad del artista ante la materia que quiere moldear" ${ }^{\text {" }}$. La tercera diversificación introductoria se indicaba por el lugar (tierra debajo de las aguas y tinieblas sobre las aguas).

La diversificación propiamente dicha está vinculada con la exégesis de los tres primeros días de la creación. Cada día representa distinto opus, la obra ${ }^{58}$. Entre esas obras de la diversificación en primer lugar fue creada la luz como la "más común" a todos los seres. Sin embargo, el motivo del firmamento (distinto del "cielo" creado el primer día) llamará más la atención del Aquinate exégeta quien haciendo un resumen de las opiniones de los Padres de la Iglesia, quienes interpretaban el firmamento como "cielo sideral" (Juan Damásceno) en oposición al cielo del primer día que era el esférico sin estrellas; "cielo corporal" o el aire mismo (Agustín); o la intuición de Juan Crisóstomo que mantenía que el autor del libro del Génesis se comporta como uno que cuenta la construcción de una casa grande: primero comenta que ha sido construida la casa y luego detalla todos los elementos con los cuales fue hecho el edificio. Así actúa el autor inspirado: primero de manera general habla sobre la creación para pasar enseguida a los detalles de la descripción ${ }^{59}$.

En esta clave y como siempre en diálogo con las anteriores interpretaciones patrísticas, Tomás comenta la separación de las aguas sobre y debajo del firmamento, rechazando la explicación alegórica de Orígenes, como si las aguas sobre el firmamento fueran las sustancias espirituales: el Aquinate las

55 S. Th., I, q. 66, a. 1, ad 5: "No nombra el aire y el fuego, porque para aquella ruda gente a la que hablaba Moisés ya no resultaba tan evidente que sean cuerpos como lo son la tierra y el agua".

56 Por. K. Seeskin, Maimonides and Aquinas on Creation, "Medioevo" 23 (1997), 453-472.

57 S. Th., I, q. 66, a. 1 , ad 5.

58 Cfr. L. Derousseaux, L'idée de création dans la pensée de Thomas d’Aquin, "Mélanges de science religieuse“ 55 (1998), 59-72.

59 S. Th., I, q. 68, a. 1, ad 1. 
interpreta como aguas en su aspecto físico, aunque es consciente de que su comprensión va vinculada con la anterior interpretación del "firmamento"60. La separación se inscribe ya en una cierta visión del mundo y su lógica. Tomás hace una advertencia ante una lectura superficial del libro del Génesis (considerando superficie tenus litteram Genesis), que no busca la explicación del sentido en el ambiente y el tiempo cuando el texto fue escrito (Aquinate admite la autoría de Moisés y su época como el tiempo de la redacción del relato sobre la creación del Gen 1,1-2,3) y también a los "destinatarios" de la Revelación y su capacidad intelectual, sino intenta confirmar forzosamente las opiniones de los filósofos de la antiguedad ${ }^{61}$.

$\mathrm{Al}$ analizar la obra del tercer día de la creación según el relato del Génesis, santo Tomás recuerda dos principales perspectivas hermenéuticas que se formaron en la historia de la exégesis cristiana en relación al orden de las actividades creadoras presentadas en Gen 1,1-2,3: se puede admitir dos órdenes, el de duración y el de la naturaleza de las cosas. Lo que llama la atención a santo Tomás es la falta en el relato de lo ocurrido al tercer día, el verbo que haría referencia al 'crear'. Es la consecuencia de la lógica del relato, porque después de la formación del cuerpo más alto - cielo, y relacionado con él el tiempo (que según la idea de Aristóteles es el "número de movimientos" y se mide por el movimiento del cielo), el segundo día tuvo lugar la separación de las aguas el cuerpo "mediano", no obstante el tercer día el cuerpo "final", es decir la tierra: Así se hizo la diversificación en la parte más baja y que es llamada tierra y mar"62. La decoración con las plantas finaliza la obra de la diversificación, aunque la misma aparición de las plantas exige una explicación de por qué no dieron fruto en seguida. Tomás encuentra dos explicaciones: la primera se remite a la idea de la creación en la causa ("fueron hechos causalmente"63), es decir, las plantas recibieron la capacidad para producir los frutos ${ }^{64}$. La segunda interpretación se basa en la distinción entre establecer y multiplicarse que

60 Cfr. O. H. Pesch, Schöpfungslehre und Schöpfungsperspektive in der Theologie des Thomas von Aquin, "Kerygma und Dogma" 49/1 (2003) 2-23; sobre la relación de la exégesis de santo Tomás con los Padres de la Iglesia, cfr. G. Dahan, Les Pères dans l'exégèse médiévale de la Bible, "Revue des Sciences Philosophiques et Théologiques" 91/1 (2007), 109-128.

61 S. Th., I, q. 68, a. 3c.

62 S. Th., I, q. 69, a. 1c.

63 S. Th., I, q. 69, a. 3c; cfr. un estudio que muestra el contexto del pensamiento tomasiano en esta materia: B. Decossas, Les exigences de la causalité créatrice selon l'«Expositio in librum de causis» de Thomas d'Aquin, "Revue thomiste" 94 (1994), 241-272.

64 S. Selner, The metaphysics of creation in Thomas Aquinas' De potentia Dei, UMI, Ann Arbor 1998. Santo Tomás se basa aqui en la idea agustiniana de rationes seminales, muy conocida en su época. 
ocurrió más tarde. La diversificación entonces, según santo Tomás, se refiere a las tres consecuencias del crear, que corresponden a los tres primeros días: cielo, agua y tierra.

\subsubsection{Opus ornatus}

A partir del cuatro día de la creación empieza la obra de la "ornamentación del mundo" o su decoración que abarca los tres días siguientes del relato: la creación de los cuerpos lucientes en el cielo (cuerpo de arriba), pájaros y peces que "decoran" el agua y el aire (cuerpo de en medio) y los animales terrestres (cuerpo de abajo) ${ }^{65}$. Esta obra se distingue del trabajo de finalización o perfección, porque no se refiere a lo interior, sino exterior. Además, la ornamentación tiene un distintivo importante: se refiere al movimiento en el cielo y en la tierra. Como finaliza la acción creadora de Dios y contiene la creación del hombre, Tomás la llama consummatio quaedam creationis ${ }^{66}$. Aquí la exégesis de nuestro autor abre una gran reflexión sobre la dignidad del hombre que fue creado a imagen de Dios: es imagen de Dios en lo que supera a todas las demás criaturas, es decir en su capacidad intelectual ${ }^{67}$. Acordándose de la destacada posición de la vida intelectual en la antropología tomista, nos damos cuenta de que el tema sólo se empieza en esta frase del Génesis.

La ornamentación del mundo no es un antropomorfismo, sino una luz sobre la creación percibida en su dinámica. También se convierte en una afirmación de la bondad de Dios que se transmite a la creación: "vió Dios que era bueno"68. Este frase de valor metafísico importante ha marcado el modo de pensar de nuestro autor.

Al terminar la exégesis del relato sobre la creación, merece la pena fijar nuestra atención en un detalle importante que puede pasar desapercibido y sin embargo muestra una convicción fundamental para santo Tomás de Aquino. Los argumentos que aparecen en sed contra - dentro de la estructura de la quaestio medieval - son los que santo Tomás considera más fuertes. Cuando en-

65 S. Th., I, q. 70, a. 1c.

66 De Potentia, q. 5, a. 9; cfr. M. D. Philippe, Saint Thomas et le mystère de la création: une réponse aux interrogations de l'homme d'aujourd'hui, "Sapientia" 52 (1997), 145-158.

67 S. Th., I, q. 3, a. 1 ad 2; sobre la interpretación de la idea del hombre como imago Dei en santo Tomás que tiene varios niveles de interpretación (imagen natural y sobrenatural etc.), vid. E. Reinhardt, La dignidad del hombre en cuanto imagen de Dios. Tomás de Aquino ante sus fuentes, Eunsa, Pamplona 2005, 45-60 (donde hace el análisis de los lugares en los cuales aparece esta cita bíblica de Gen 1,26-27.

68 M. Kehl, Contempló Dios toda su obra y estaba muy bien: una teología de la creación, Herder, Barcelona 2009. 
tonces se detiene para analizar el texto inspirado del Gen, como argumento a favor de su exégesis pone una "autoridad" de la Sagrada Escritura ("es suficiente con la autoridad de la Escritura"). De ahí viene que Tomás preste atención a distintos modos de hablar de la Escritura (modus dicendi) - tema que explica con detenimiento en el prólogo de su comentario a los Salmos ${ }^{69}$.

\section{Conclusiones}

Creación (creatio) es una acción libre de Dios que más que un acontecimiento, con un "antes" y un "despúes" establece una relación entre lo que es Dios y lo que no lo es. Se trata de una postura que percibe todo en relación con Dios. Tomás presta mucha atención en explicar esta fundamental relatio que describe la esencia de la creación en sentido bíblico. No obstante, la assimilatio describe el carácter y consecuencias de esta relación de Dios con su criatura, ya que su Creador puede verla siempre en su "desnudez", tal como es.

Al considerar el relato del Gen 1,1-2,1, santo Tomás ofrece una exégesis madura y profundamente trinitaria ${ }^{70}$. No se trata únicamente de la alusión al "espíritu de Dios" que estaba sobre las aguas, sino de una perspectiva que situa la creación en el horizonte de las eternas procedencias intratrinitarias. De ellas nace una procedencia (processio) temporal ad extra que es la creación. Crear entonces no significa hacer una sola vez, sino participar - gracias al acto divino libre y generoso - en la vida trinitaria. Esta óptica nos hace leer con más detenimiento sobre todo el tratado de la Trinidad, tal como lo sugiere G. Emery, para encontrar en ella las claves para el tema de la creación.

La creación significa también el resultado mismo de la acción de Dios que abarca toda la realidad, no excluyendo el mundo material ni tampoco espiritual de los ángeles, de la relación con Dios. La exégesis del Gen 1,1-2,1 tal como la propone santo Tomás saca a la luz la fundamental afirmación de la dependencia de todo lo creado por Dios ${ }^{71}$. Todo lo que existe depende en su

69 In Ps., prologus.

70 Cfr. M.-J. Nicolas, Le Christ et la création d'après saint Thomas d'Aquin, Studia mediaevalia et mariologica P. C. Balic o.f.m. septuagesimum explenti annum dicata, Rome 1971, 79-100.

71 Cfr. O. Boulnois, Création, contingence et singularité de Thomas d'Aquin à Duns Scot, en: J. Greisch (éd.), Création et événement, Éditions de 1'Institut supérieur de Philosophie, Peeters, Louvain-Paris 1996, 3-20. 
existencia de Dios, porque al final es habens esse. Es algo que espontáneamente desea cada ser creado - existir (desiderium essendi) ${ }^{72}$.

La triple estructura de la creación (creatio - distinctio - ornatio) expresa de distintas maneras la perfección de la obra de Dios y su sabiduría ${ }^{73}$.

\section{Summary}

Thomas Aquinas is one of those medieval theologians, whose biblical commentaries, especially dedicated to the books of the Old Testament, are still waiting to be discovered for the study. Biblical style of his theology ("sacra doctrina" in Middle Age) is expressed not only by St. Thomas's scriptural comments, which are as important's record of his university lectures, but also interesting exegetical proposals, which we find in his systematic works (eg. Summa theologiae). Medieval workshop of biblist is based on the fundamental principle of the unity of the salvific plan, and is situated always in the context of tradition, with originality, however, surprising look, who wishes to remain universalist (hence the search for help in philosophy and its terminology). A clear example of the master's style of exegesis of Aquinas is the interpretation of the description of creation in Genesis 1,1-2,1, referring to the three basic models of understanding the essence of the creative act and its consequences: relation, assimilation or procession. This triad of concepts is needed to fully discover for understand Thomas's interpretation of Genesis 1,1-2,1 based on a triple work made by God: opus creationis, distinctionis et ornatus. Once again, Thomas reveals the same line exegesis of his program: the priority of literal sense, which is descover the sense (sensus) and not a fundamentalist reading.

The creation according Thomas Aquinas is a free act of God, which calls into existence the universe from nothing (ex nihilo), but also keeps it in existence (creatio continua). It covers the whole of reality, both material and spiritual, so present a fundamental relationship of creation with the Creator, because everything has its existence from Him (habens esse). In terms of ad extra, the creation is a communication of kindness, should be viewed in the perspective of the Trinity. Creation as temporal procession ad extra is an prolongation of the eternal procession ad intra. That is why Thomas assigns creative and saving action to the Holy Spirit. The multiplicity of creation is a way of participation in the Trinitarian life.

72 G. Stancato, Le concept de désir dans l'ouvre de Thomas d'Aquin analyse lexicographique et conceptuelle du mot desiderium, Vrin, Paris 2011.

73 In Haeb., cap. IV, lect. 1. 


\section{Streszczenie}

Tomasz z Akwinu należy do grona tych średniowiecznych teologów, których komentarze biblijne, zwłaszcza poświęcone księgom Starego Testamentu, wciąż czekają na odkrycie i dogłębne studium. Biblijny styl sacra doctrina nie wyraża się jedynie w pozostawionych przez św. Tomasz komentarzach, będących co istotne zapisem jego uniwersyteckich wykładów, ale także ciekawymi propozycjami egzegetycznymi, które możemy odnaleźć w jego dziełach systematycznych (np. w Sumie teologii). Warsztat egzegety średniowiecznego opiera się na fundamentalnej zasadzie jedności planu zbawczego i wpisuje się zawsze w kontekst Tradycji, zaskakując jednak oryginalnością spojrzenia, które pragnie pozostać spojrzeniem uniwersalistycznym (stąd szukanie pomocy w filozofii i jej terminologii). Czytelnym przykładem stylu egzegezy mistrza z Akwinu jest interpretacja opisu stworzenia świata $\mathrm{z} R \mathrm{Rdz} 1,1-2,1$, nawiązująca do trzech zasadniczych modeli rozumienia istoty aktu stwórczego i jego konsekwencji: jako relacja, asymilacja lub pochodzenie. Ta triada pojęć jest niezbędna, aby w pełni odkryć bogactwo Tomaszowej wykładni Rdz,1,1-2,1, opartej na potrójnym dziele dokonanym przez Boga: opus creationis, distinctionis et ornatus. Raz jeszcze Tomasz ujawnia tym samym swoją programową linię egzegezy: priorytetu sensu literalnego, którego dosłowność polega na odczytania „sensu”, a nie fundamentalistycznej lekturze.

Stworzenie dla Tomasza to wolny akt Boga, który powołuje do istnienia wszechświat z niczego (ex nihilo), ale także utrzymuje go w istnieniu (creatio continua). Obejmuje całą rzeczywistość, zarówno materialną i duchową, wyrażając tym samym podstawową zależność stworzenia od Stwórcy: wszystko bowiem posiada swoje istnienie od Niego (habens esse). W aspekcie ad extra, stworzenie jest komunikacją dobroci i jako takie winno być postrzegane w perspektywie trynitarnej. Stworzenie, będąc czasowym pochodzeniem ad extra jest przedłużeniem odwiecznych pochodzeń ad intra w Trójcy Św. Dlatego to Duchowi Świętemu przypisuje Tomasz działanie stwórcze i zbawcze. Wielość stworzenia jest uczestnictwem w pełni życia trynitarnego. 